\title{
Two Types of Mid-Latitudes Responses during La Niña
}

\author{
Masahiro Shiozaki ${ }^{1}$ and Takeshi Enomoto ${ }^{2,3}$ \\ ${ }^{1}$ Research Institute for Applied Mechanics, Kyushu University, Kasuga, Japan \\ ${ }^{2}$ Disaster Prevention Research Institute, Kyoto University, Uji, Japan \\ ${ }^{3}$ Application Laboratory, Japan Agency for Marine-Earth Science and Technology, Yokohama, Japan
}

\begin{abstract}
La Niña cases that occurred after 1948 are classified into cold and non-cold winters in the Far East to investigate the formation of disparate teleconnection patterns corresponding to the two types and to compare with those during El Niño. According to composite analyses using reanalysis datasets, the North Pacific Oscillation (NPO)/western Pacific (WP) pattern (NPO/WP pattern) and the Pacific-North American (PNA) pattern dominate in the cold and non-cold winters, respectively. As during El Niño, modulations of the local Hadley circulation associated with La Niña play an important role in the formation of the teleconnection patterns. These results indicate that the formation mechanisms of teleconnection patterns during La Niña are the same as those during El Niño but are not simple reverse signals.
\end{abstract}

(Citation: Shiozaki, M., and T. Enomoto, 2021: Two types of mid-latitudes responses during La Niña. SOLA, 17, 103-108, doi: 10.2151/sola.2021-016.)

\section{Introduction}

Teleconnection patterns often appear during El Niño/Southern Oscillation (ENSO) due to the modulation of the tropical convection. Kodera (1998) distinguished two types of El Niño based on the dominating teleconnection pattern: one based on the western Pacific (WP) pattern and the other based on the Pacific-North American (PNA) pattern (Wallace and Gutzler 1981). He also highlighted the difference of tropical sea surface temperature (SST) anomaly in the central Pacific Ocean but discussed the excitation mechanism of the two teleconnection patterns based on snowfall in Eurasia.

North Pacific Oscillation (NPO) is defined by the seesaw in sea level pressure (SLP) over Aleutian and Hawaii (Walker and Bliss 1932). The WP pattern and the NPO have a resemblance in terms of meridional dipoles in the north Pacific Ocean. Linkin and Nigam (2008) did not distinguish the WP pattern from the NPO, and thus, named the two teleconnection patterns NPO/WP. However, using partial correlation, Tanaka et al. (2016) showed that the WP pattern and the NPO are different variation patterns. The empirical orthogonal function (EOF) analysis performed by Linkin and Nigam (2008) indicates that the two teleconnection patterns in the North Pacific Ocean could not be separated because their centers of action are close to each other.

Shiozaki et al. (2020) showed that the WP (PNA) pattern dominates in El Niño cases that are associated with warm (nonwarm) winters in the Far East. The modulation of the local Hadley circulation corresponding to the tropical SST anomaly distributions plays an important role in the excitation of the different teleconnection patterns. Horii and Hanawa (2004) classified El Niño cases into spring-type and summer-fall type based on the onset timing and developing process. The warm and the non-warm winter cases during El Niño may be consistent with those types, respectively. However, the two above-mentioned studies do not consider La Niña.

Recent studies have revealed that the atmospheric responses to

Corresponding author: Masahiro Shiozaki, Research Institute for Applied Mechanics, Kyushu University, 6-1 Kasuga-koen, Kasuga, Fukuoka, 8168580, Japan. E-mail: shiozaki.masahiro.27e@kyoto-u.jp.
El Niño and La Nina are asymmetrical. Hoerling et al. (1997) investigated nonlinearity of atmospheric responses of ENSO. They discussed that the different distribution of tropical precipitation anomalies between El Niño and La Niña is the cause of nonlinear behavior. The second center of action of the PNA pattern in La Niña is shifted slightly westward compared to that in El Niño (DeWeaver and Nigam 2002; Cao et al. 2019). Additionally, Zhang et al. (2014) pointed out that the asymmetric component exhibited by the sum of El Niño and La Niña has been a fundamental feature of the events since 1984. However, the impacts of tropical SST on the asymmetry remain as research problems.

Halpert and Ropelewski (1992) pointed out that winter climates in Japan tend to be colder than normal from November to May during when Southern Oscillation Indices (Trenberth 1976; Ropelewski and Jones 1987) are positive, corresponding to the La Niña phase. However, according to the Japan Meteorological Agency (JMA) statistics, this tendency does not apply in some La Niña cases that occurred after 1948. Thus, this study aims to confirm whether the excitation mechanism of disparate teleconnection patterns during El Niño (Shiozaki et al. 2020) applies to that during La Niña.

The datasets and analysis methods used for this study are presented in Section 2, while Section 3 describes results and comparison of the three classifications. In Section 4, we discuss the differences in atmospheric responses between the three classifications and their causes, based on SST anomaly and related convection.

\section{Datasets and methods}

The SST and atmospheric datasets used in this study are the monthly Extended Reconstructed Sea Surface Temperature (ERSST) v5 data (Huang et al. 2017) on a $2.0^{\circ} \times 2.0^{\circ}$ horizontal grid obtained from the National Oceanic and Atmospheric Administration (NOAA) and the reanalysis-1 data (Kalnay et al. 1996) on a $2.5^{\circ} \times 2.5^{\circ}$ horizontal grid obtained from the National Centers for Environmental Prediction (NCEP)/National Center for Atmospheric Research (NCAR), respectively.

Adopting the La Niña definition given by the JMA based on the SST in NINO. $3\left(5^{\circ} \mathrm{S}-5^{\circ} \mathrm{N}, 90^{\circ} \mathrm{W}-150^{\circ} \mathrm{W}\right)$, we identify La Niña cases from 1948 to $2017 / 18$. The definition is such that the 5 -month running mean SST anomalies for NINO.3 continue to be $-0.5^{\circ} \mathrm{C}$ or lower for six consecutive months or longer. The SST anomalies in NINO.3 are defined as deviations from the latest sliding 30 years. The identified La Niña cases are classified into cold and non-cold winter cases based on the sign of the $850-\mathrm{hPa}$ temperature anomaly in the Far East $\left(25^{\circ} \mathrm{N}-40^{\circ} \mathrm{N}, 100^{\circ} \mathrm{E}-140^{\circ} \mathrm{E}\right)$. This region can capture the variability of the eastern Asian winter monsoon (Takaya and Nakamura 2013; Shiozaki et al. 2020).

Composite analyses have been conducted for all La Niña cases (ALL) and for each of these two categories. Anomalies have been calculated after removing a linear trend. This warming trend has been calculated at each grid point using the least-squares method. The Student's t-test and Welch's t-test have been applied to confirm the statistical significance of the composite analyses and the difference between the cold and the non-cold winter cases, respectively.

Teleconnection pattern indices defined by Wallace and Gutzler (1981) are calculated for comparison with the teleconnection 
(a)

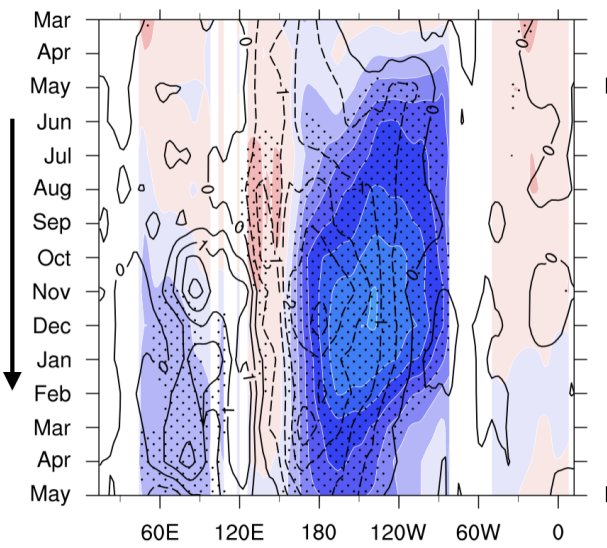

(b)

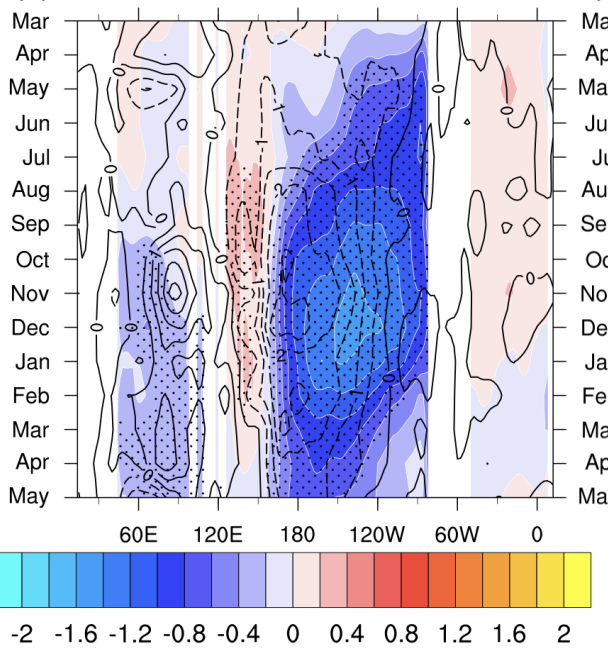

(c)

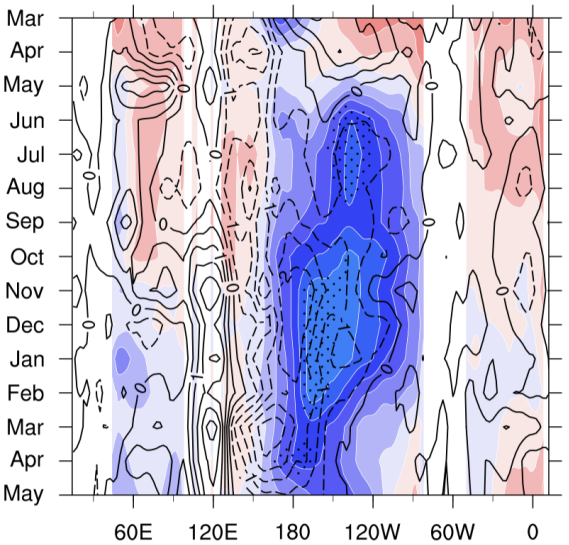

Fig. 1. Temporal evolution of the SST (color shades; units of K) and zonal wind (contours; $\mathrm{m} \mathrm{s}^{-1}$ ) anomalies at the 925 -hPa surface averaged between $5^{\circ} \mathrm{N}$ and $5^{\circ} \mathrm{S}$ for (a) ALL, (b) cold, and (c) the non-cold winter cases. The hatches show the SST anomalies with a statistical significance of $90 \%$.

pattern intensities. Furthermore, to investigate the influence of convection in the Tropics associated with SST anomalies on the teleconnection patterns, the Rossby wave source anomaly (Sardeshmukh and Hoskins 1988) under the assumption of negligible friction and the wave activity flux for zonally non-uniform basic fields under the quasi-geostrophic balance (Takaya and Nakamura 2001) has been analyzed in the upper-troposphere, same as Shiozaki et al. (2020).

\section{Results}

Fifteen La Niña cases were identified from 1948 to 2017/18. Ten (five) cases are classified as cold (non-cold) winter cases, which is roughly consistent with the ratio of warm and nonwarm winter cases in the Far East during El Niño (Shiozaki et al. 2020). The cold winter cases include 1954/55, 1955/56, 1970/71, $1973 / 74,1975 / 76,1995 / 96,1999 / 2000,2007 / 08,2010 / 11$ and $2017 / 18$ cases, whereas the others include 1948/49, 1949/50, 1964/65, 1988/89 and 1998/99 cases. The characteristics of each category and the differences in the responses during El Niño are as follows.

\subsection{Differences in the development of La Niña}

Figure 1 shows the developmental process of La Niña for each classification. In ALL (Fig. 1a), La Niña occurs in late spring, and in early fall a negative SST anomaly in the eastern Pacific Ocean extends to around $160^{\circ} \mathrm{E}$ beyond the dateline. The peak of the SST anomaly $\left(130^{\circ} \mathrm{W}-140^{\circ} \mathrm{W}\right)$ is shifted westward compared with that of El Niño $\left(120^{\circ} \mathrm{W}\right.$, Shiozaki et al. 2020). The positive SST anomaly in the Philippine Sea is dominant from summer to fall. Furthermore, in the Indian Ocean, the basin cooling onset occurs in late fall. Wind anomalies in the lower troposphere are easterly in the Pacific Ocean and westerly in the Indian Ocean, peaking in November. These wind anomalies indicate the enhancement of the Walker circulation and are consistent with the distribution of SST anomalies.

In the cold winter cases (Fig. 1b), La Niña occurs in spring and the statistically significant negative SST anomaly in the eastern Pacific Ocean crosses the dateline in summer. The amplitude of the negative anomaly is larger and the anomaly lasts longer than that in ALL. Moreover, the SST in the Philippine Sea persists in the positive anomaly from the developing summer to winter.

In sharp contrast, in the non-cold winter cases (Fig. 1c), a positive SST anomaly like El Niño exists before the onset of La Niña and the influence remains in the Indian Ocean. The ENSO

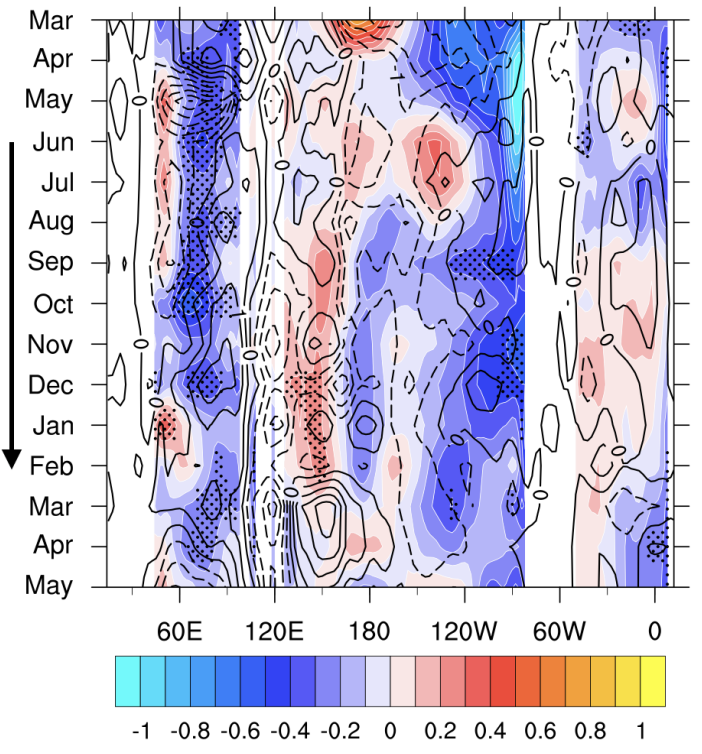

Fig. 2. Same as Fig. 1, but the differences between the cold and the noncold winter cases.

phase proceeds to La Niña at around $150^{\circ} \mathrm{W}$ in summer. In the developing fall, the negative SST anomaly crosses the dateline and the amplitude of the positive SST anomaly in the Philippine Sea becomes smaller.

Figure 2 shows the SST and the lower-troposphere zonal wind anomalies differences between the cold and the non-cold winter cases. In the Pacific Ocean, the differences of the SST anomaly are remarkable for the region near the South American continent and near $160^{\circ} \mathrm{E}$. The modulation of the Walker circulation is also clear, corresponding to the SST anomaly. Furthermore, in the Indian Ocean, the differences persist from the developing to the decaying seasons.

\subsection{The SST anomaly distributions in winter}

Wang et al. (2000) pointed out that the negative SST anomaly in the Philippine Sea during El Niño contributes to the warm winter in East Asia by exciting anticyclonic circulation. To confirm whether this mechanism works during La Niña, we investi- 

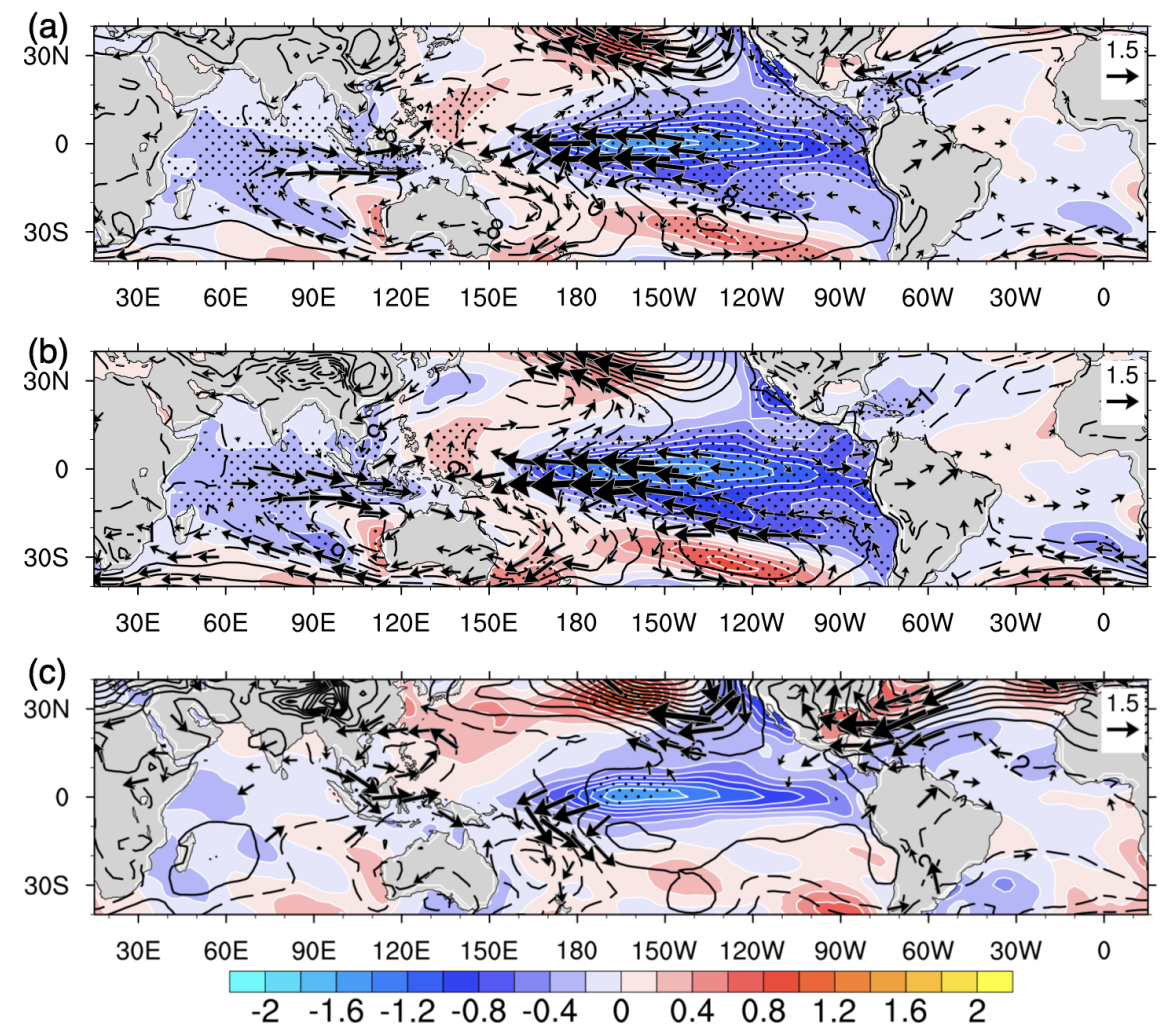

Fig. 3. SST (color shades; units of K), SLP (contours; hPa), and 850-hPa wind (arrows; $\mathrm{m} \mathrm{s}^{-1}$ ) anomalies in the DJF composite for (a) ALL, (b) cold winter, and (c) non-cold winter cases, respectively. The arrows and hatches show the wind and the SST anomalies with a statistical significance of $90 \%$.

gate the SST anomaly distribution in the mature phase of La Niña. In ALL and the cold winter cases for the December-JanuaryFebruary (DJF) mean (Figs. 3a and 3b), the positive SST anomaly and cyclonic circulation in the Philippine Sea are predominant, consistent with the antiphase of Wang's mechanism. Furthermore, the Indian Ocean Basin cooling and the modulation of the Walker circulation indicated by a convergence of lower-troposphere wind anomalies are consistent with the antiphase of the development mechanism of the anticyclonic circulation in the Philippine Sea caused by the modulation of Walker circulation during El Niño (Watanabe and Jin 2002).

Contrarily, in the non-cold winter cases (Fig. 3c), the amplitudes of the SST positive anomaly in the Philippine Sea and the Indian Ocean basin cooling are small. Therefore, the modulation of the Walker circulation is weaker than that in the cold winter cases, though the cyclonic circulation in the South China Sea $\left(20^{\circ} \mathrm{N}, 120^{\circ} \mathrm{E}\right)$ is predominant. Overall, easterly wind anomalies dominate in East Asia owing to the extent of the cyclonic circulation being limited in the south of $20^{\circ} \mathrm{N}$.

\subsection{Teleconnection patterns}

Figure 4 shows the 850 -hPa temperature anomalies and the 500 -hPa height anomalies for the DJF mean. For ALL at 850$\mathrm{hPa}$ (Fig. 4a), the southerly wind anomaly is predominant in the Far East, whereas the negative temperature anomaly does not exhibit statistical significance. At the $500-\mathrm{hPa}$ surface (Fig. 4b) and teleconnection pattern indices (Table 1), the PNA pattern is predominant. The height anomalies coincide with the centers of action defined for the PNA pattern, which are shifted westward than those during El Niño (DeWeaver and Nigam 2002; Cao et al. 2019; Shiozaki et al. 2020).

In the cold winter cases (Fig. 4c), the negative temperature anomaly is distributed in East Asia and Siberia with statistical significance. Although the PNA pattern is not clear, the height anomalies are distributed in the meridional dipole, exhibiting a combination of the NPO and the WP pattern in the North Pacific
Ocean (Fig. 4d and Table 1). Hereafter, this meridional dipole is referred to as the NPO/WP pattern in this paper.

In the non-cold winter cases, large amplitudes of the positive temperature anomalies (Fig. 4e) are distributed throughout East Asia and Siberia. The PNA pattern (Fig. 4f) is statistically insignificant but the PNA pattern indices of four out of five cases are smaller than -0.85 (figures omitted). This value is far smaller than that in the cold winter cases (Table 1). The PNA pattern in this category is conspicuous because the height anomalies in this category are very close to the centers of action of the PNA pattern. The asymmetry of ENSO in the phase of the PNA pattern may indicate the difference between El Niño, in which the NPO and the WP pattern are clearly separated (Shiozaki et al. 2020), and La Niña in which the NPO and the WP pattern are combined.

\subsection{Excitation of the Rossby wave sources due to the modulated local Hadley circulation}

We also investigate the influences of the two types of La Niña on the midlatitudes atmosphere through the modulation of the Hadley circulation associated with the tropical SST anomaly distributions. Figure 5 shows the $250-\mathrm{hPa}$ height, Rossby wave source, and divergent wind anomalies for the DJF mean. In all three categories, the positive height anomalies in the Aleutian are located in the middle of the negative and positive Rossby wave source anomalies. The positive height anomalies are located downstream of the westerly jet to balance with the negative Rossby wave source. This balance is consistent with the midlatitude vorticity balance (Honda et al. 1999). The negative Rossby source anomaly is excited by the enhancement of the local Hadley circulation indicated by the divergent wind anomalies near the dateline related to enhanced Walker circulation.

In the cold winter cases (Fig. 5b), the local Hadley circulation $\left(160^{\circ} \mathrm{E}-150^{\circ} \mathrm{W}\right)$ is greatly weakened, consistent with the SST anomaly distribution (Fig. 3b). Therefore, the excited Rossby source negative anomaly is widely distributed in the North Pacific Ocean. Furthermore, convection is strengthened at $80^{\circ} \mathrm{W}-30^{\circ} \mathrm{W}$ 

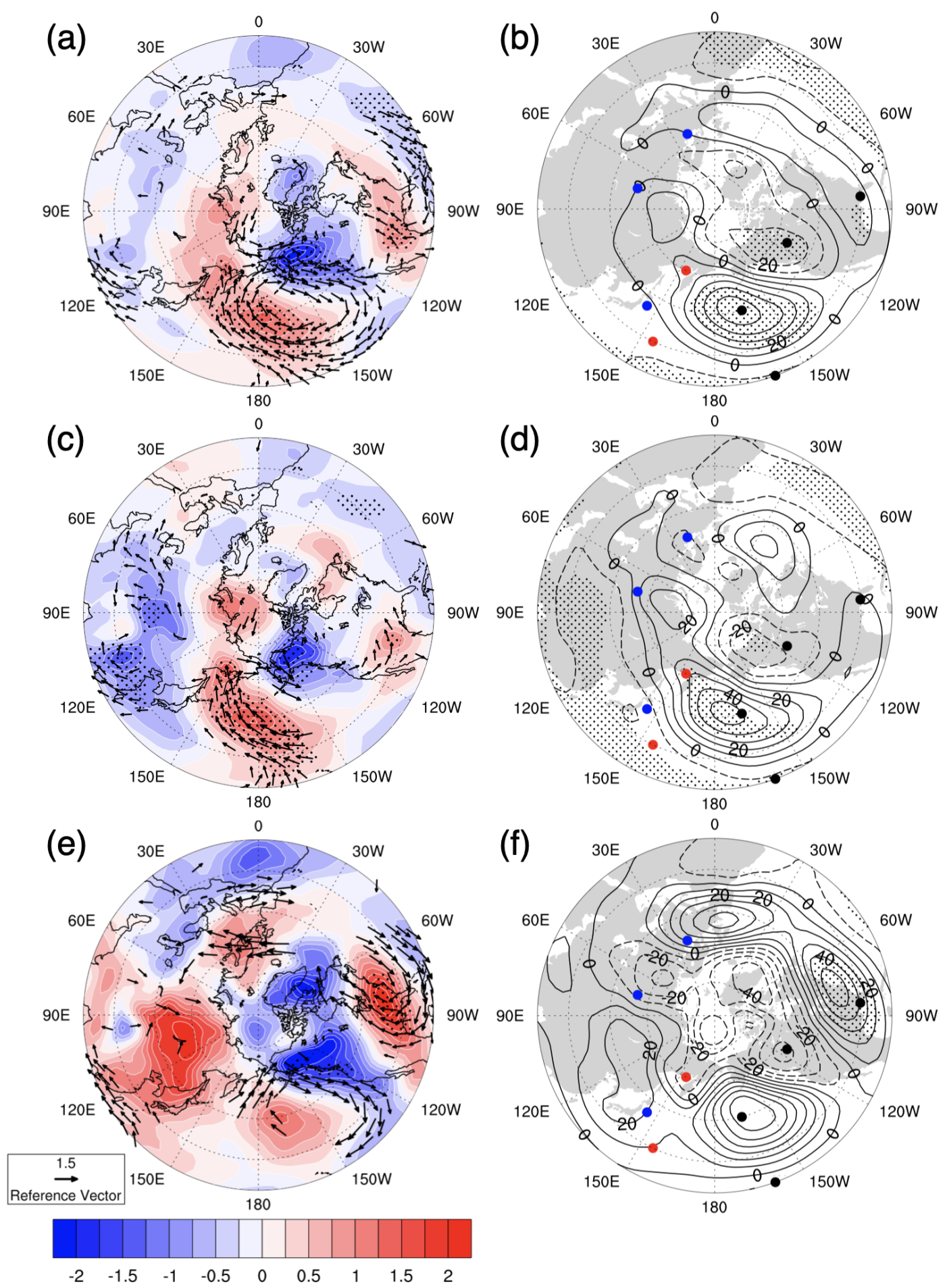

Fig. 4. The temperature anomalies (color shades; units of $\mathrm{K}$ ) and the wind anomalies (arrows; $\mathrm{m} \mathrm{s}^{-1}$ ) in the $850-\mathrm{hPa}(\mathrm{a}, \mathrm{c}$, e) and height anomalies (contours; $\mathrm{m}$ ) in the 500-hPa composites (b, d, f) for (a, b) ALL, (c, d) cold winter, (e, f) non-cold winter cases, respectively. The contour intervals are $10 \mathrm{~m}$. The arrows and hatches show the wind and the height anomalies with a statistical significance of $90 \%$. The dots in black, red, and blue indicate the centers of action of the PNA, WP, and EU patterns, respectively.

due to the large gradient of the surface temperature between the eastern Pacific Ocean and the South American continent.

In contrast, in the non-cold winter cases (Fig. 5c), the local Hadley circulation is modulated within a narrower area (around $\left.170^{\circ} \mathrm{E}-160^{\circ} \mathrm{W}\right)$ than in the cold winter cases. Therefore, the positive height anomaly in the Aleutian is shifted eastward than the cold winter cases. Furthermore, the longitudes of the strengthened local Hadley circulation (around $100^{\circ} \mathrm{W}-50^{\circ} \mathrm{W}$ ) is shifted west-
Table 1. Teleconnection pattern indices in each classification.

\begin{tabular}{crrc}
\hline & ALL & Cold & Non-cold \\
\hline PNA & -0.61 & -0.41 & -0.99 \\
WP & 0.30 & 0.61 & -0.30 \\
EU & 0.02 & 0.21 & -0.37 \\
\hline
\end{tabular}


(a)

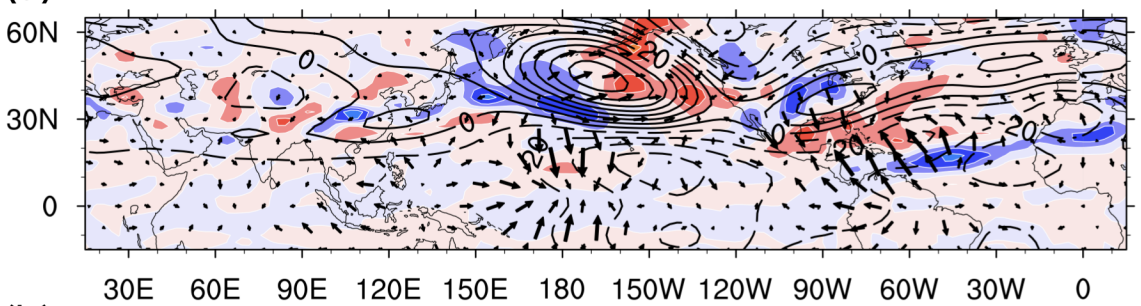

(b)

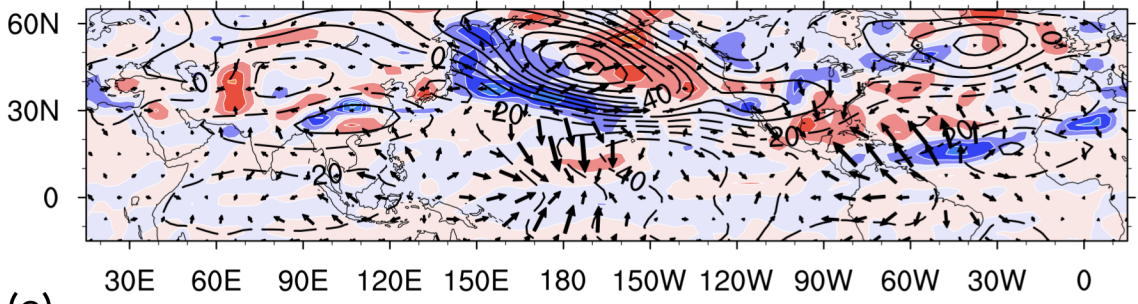

(c)

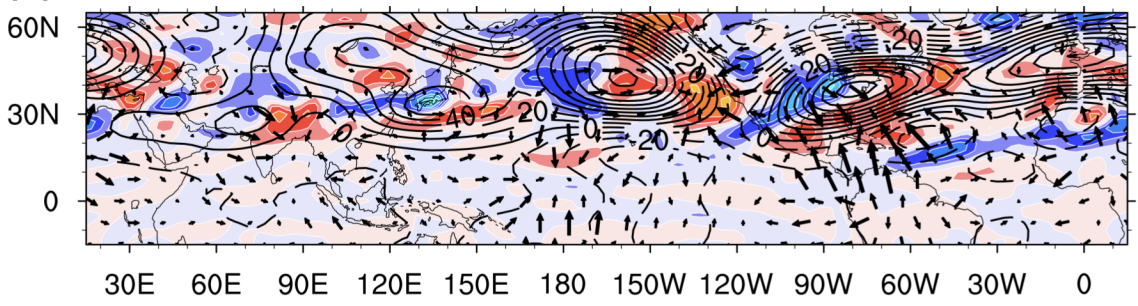

\begin{tabular}{|lllll|l|lllllll|l|l}
\hline & & & & & & & & & & $\mid$ & & .5 \\
-15 & -12 & -9 & -6 & -3 & 0 & 3 & 6 & 9 & 12 & 15 & $\rightarrow$
\end{tabular}

Fig. 5. The Rossby wave sources (color shades; $\mathrm{s}^{-2}$ ), height (contours; $\mathrm{m}$ ), and divergent wind (arrows; $\mathrm{m} \mathrm{s}^{-1}$ ) anomalies at the 250 -hPa surface in the DJF composite for (a) ALL, (b) cold winter, and (c) non-cold winter cases, respectively.
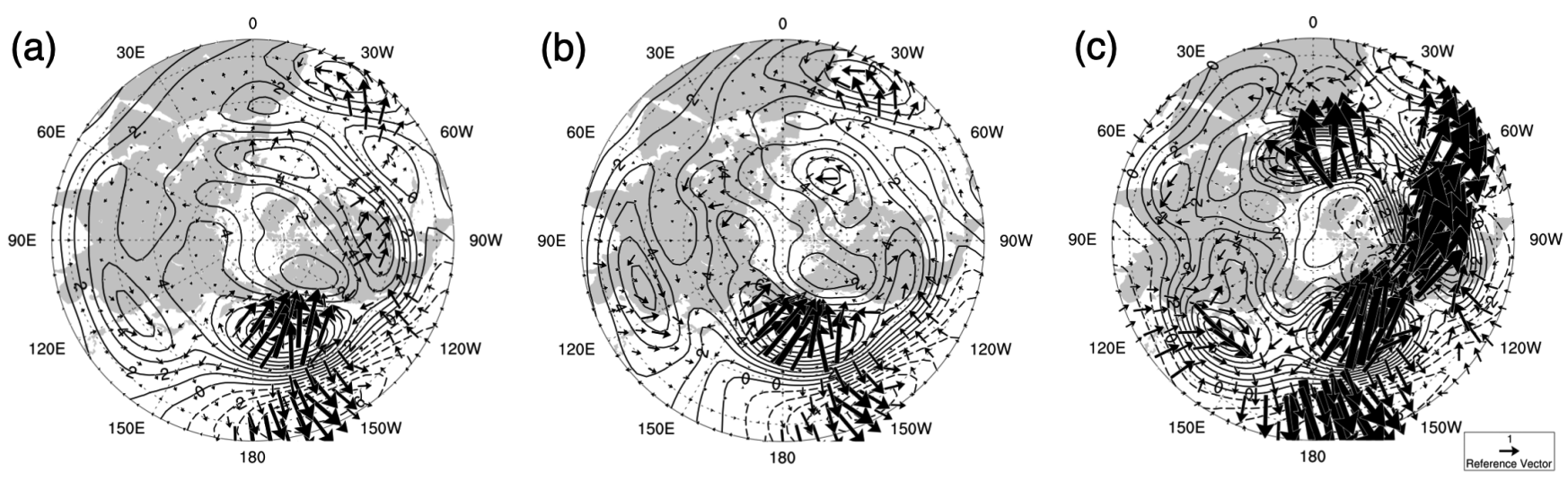

Fig. 6. Same as Figs. 4b, 4d, and 4f but for height (contours; $\mathrm{m}$ ) and wave activity flux (arrows; $\mathrm{m}^{2} \mathrm{~s}^{-2}$ ) at the 250 -hPa surface.

ward compared with the cold winter cases. The SST anomaly in the tropical Atlantic Ocean, but not shown statistical significance, may have caused the difference in the center of the divergence between two categories. The enhanced local Hadley circulation corresponds to the positive Rossby wave source anomaly located from the eastern Pacific Ocean to the northwestern Atlantic Ocean.

\subsection{Identification of wave trains by the wave activity flux}

In ALL (Fig. 6a) for the DJF mean, the dominant Rossby waves propagate from the Aleutian to North America and from North America to the northwest Atlantic Ocean corresponding to the PNA pattern. Besides, the Rossby waves propagate from $20^{\circ} \mathrm{N}$, $120^{\circ} \mathrm{W}$ to the northwest Atlantic Ocean, corresponding to the PNA pattern. This distribution of the wave activity flux is similar to that of all El Niño averages in Shiozaki et al. (2020).

In the cold winter cases (Fig. 6b), the northward flux is predominant at around $50^{\circ} \mathrm{N}, 150^{\circ} \mathrm{E}-150^{\circ} \mathrm{W}$. This northward flux in the North Pacific Ocean suggests a combination of the NPO and the WP pattern (NPO/WP pattern).

In the non-cold winter cases (Fig. 6c), the Rossby waves associated with the PNA pattern dominate from the Aleutian to the central Atlantic Ocean via North America and from $20^{\circ} \mathrm{N}, 120^{\circ} \mathrm{W}$ to the northwest Atlantic Ocean. The Rossby waves propagate downstream more extensively than that in non-warm winter cases during El Niño (Shiozaki et al. 2020). Additionally, the Rossby waves have large amplitudes from the East China Sea and the Philippine Sea to Japan and from the Scandinavian Peninsula to North Africa. The Rossby waves corresponding to the negative 
height anomaly over China during El Niño are transmitted from the Bay of Bengal and the South China Sea (Shiozaki et al. 2020) but shifted to the eastward in non-cold cases during La Niña. This flux distribution is consistent with the distribution of the Rossby wave source positive anomaly $\left(25^{\circ} \mathrm{N}-30^{\circ} \mathrm{N}, 120^{\circ} \mathrm{E}-150^{\circ} \mathrm{E}\right)$. These Rossby wave source and propagation correspond to the positive height anomaly in East Asia (Figs. $4 \mathrm{f}$ and $6 \mathrm{c}$ ). The other flux propagating from the Scandinavian Peninsula to North Africa has a larger amplitude than that during El Niño. Therefore, the blocking in Scandinavia and the height anomaly in East Asia corresponding to the Rossby waves from the East China Sea and the Philippine Sea configure a wave train resembling the EU pattern.

\section{Summary}

This study classified La Niña cases after 1948 based on cold and non-cold winters in the Far East in order to confirm whether the excitation mechanism of different teleconnection patterns during El Niño can be applied to La Niña.

We found disparate midlatitude atmospheric responses for two types of La Niña and were consistent with those in El Niño (Kodera 1998; Shiozaki et al. 2020). However, there were the following four differences as the asymmetry of ENSO: 1) The NPO/WP pattern appears in the cold winter cases, not the WP pattern; 2) The amplitude of the PNA pattern in the non-cold winter cases is larger, and the related Rossby wave propagates downstream more extensively; 3) The longitude of the large SST anomaly gradient in the tropics is shifted westward by approximately $20^{\circ}$ westward in the both cases, compared with that in the warm and non-warm winter cases during El Niño (Shiozaki et al. 2020); and 4) The influences of El Niño before the La Niña onset remain in the noncold winter cases. 1), 2), and 3) seem as the ENSO asymmetry such as the shift of the centers of action and the difference in amplitude of the midlatitudes atmosphere responses (DeWeaver and Nigam 2002; Feng et al. 2017; Cao et al. 2019). 3) and 4) are consistent with the fact that the SST anomalies in the Pacific and Indian Oceans modulate the Walker and the local Hadley circulations, which excite different midlatitude atmospheric responses (Watanabe and Jin 2002; Shiozaki et al. 2020). With regard to 4), the difference in La Niña onset between cold and non-cold winter cases is notable. Therefore, these results indicate that the formation of teleconnection patterns during La Niña is the same as that during El Niño but not a simple reverse of the sign.

The number of La Niña cases is insufficient to discuss the statistical significance. Therefore, a natural extension to this study would be an analysis using large-scale ensemble experimental data and numerical experiments based on the SST anomaly distributions of the two types of La Niña.

\section{Acknowledgments}

We would like to thank anonymous reviewers for their useful comments. This study was supported by the Japan Society for the Promotion of Science (JSPS) KAKENHI (Grant No.19H05698). The NOAA ERSST V5 data and NCEP Reanalysis data were provided by the NOAA/OAR/ESRL PSD, Boulder, Colorado, USA, from their Web site at https://www.esrl.noaa.gov/psd/. NCEP Reanalysis data provided by the NOAA/OAR/ESRL PSL, Boulder, Colorado, USA, from their Web site at https://psl.noaa.gov/.

Edited by: Y. Takaya

\section{References}

Cao, D., Q. Wu, A. Hu, Y. Yao, S. Liu, S. R. Schroeder, and F. Yang, 2019: Linear and nonlinear winter atmospheric responses to extreme phases of low frequency Pacific sea surface temperature variability. Climate Dyn., 52, 49-68.

DeWeaver, E., and S. Nigam, 2002: Linearity in ENSO's atmo- spheric response. J. Climate, 15, 2446-2461.

Feng, J., W. Chen, and Y. Li, 2017: Asymmetry of the winter extra-tropical teleconnections in the Northern Hemisphere associated with two types of ENSO. Climate Dyn., 48, 2135-2151.

Halpert, M. S., and C. F. Ropelewski, 1992: Surface temperature patterns associated with the Southern Oscillation. J. Climate, 5, 577-593.

Hoerling, M. P., A. Kumar, and M. Zhong, 1997: El Niño, La Niña, and the nonlinearity of their teleconnections. J. Climate, 10, 1769-1786.

Honda, M., K. Yamazaki, H. Nakamura, and K. Takeuchi, 1999: Dynamic and thermodynamic characteristics of atmospheric response to anomalous sea-ice extent in the Sea of Okhotsk. J. Climate, 12, 3347-3358.

Huang, B., P. W. Thorne, V. F. Banzon, T. Boyer, G. Chepurin, J. H. Lawrimore, M. J. Menne, T. M. Smith, R. S. Vose, and H.-M. Zhang, 2017: Extended reconstructed sea surface temperature, Version 5 (ERSSTv5): Upgrades, validations, and intercomparisons. J. Climate, 30, 8179-8205.

Kalnay, E., M. Kanamitsu, R. Kistler, W. Collins, D. Deaven, L. Gandin, M. Iredell, S. Saha, G. White, J. Woollen, Y. Zhu, M. Chelliah, W. Ebisuzaki, W. Higgins, J. Janowiak, K. C. Mo, C. Ropelewski, J. Wang, A. Leetmaa, R. Reynolds, R. Jenne, and D. Joseph, 1996: The NCEP/NCAR 40-year reanalysis project. Bull. Amer. Meteor. Soc., 77, 437-472.

Kodera, K., 1998: Consideration of the origin of the different midlatitude atmospheric responses among El Niño events. $J$. Meteor. Soc. Japan, 76, 347-361.

Linkin, M. E., and S. Nigam, 2008: The North Pacific oscillationWest Pacific teleconnection pattern: Mature-phase structure and winter impacts. J. Climate, 21, 1979-1997.

Ropelewski, C. F., and P. D. Jones, 1987: An extension of the Tahiti-Darwin Southern oscillation index. Mon. Wea. Rev., 115, 2161-2165.

Sardeshmukh, P. D., and B. J. Hoskins, 1988: The generation of global rotational flow by steady idealized tropical divergence. J. Atmos. Sci., 45, 1228-1251.

Shiozaki, M., T. Enomoto, and K. Takaya, 2020: Disparate midlatitude responses to the Eastern Pacific El Niño. J. Climate, 34, 773-786.

Takaya, K., and H. Nakamura, 2001: A formulation of a phase-independent wave-activity flux for stationary and migratory quasigeostrophic eddies on a zonally varying basic flow. $J$. Atmos. Sci., 58, 608-627.

Takaya, K., and H. Nakamura, 2013: Interannual variability of the East Asian winter monsoon and related modulations of the planetarywaves. J. Climate, 26, 9445-9461.

Tanaka, S., K. Nishii, and H. Nakamura, 2016: Vertical structure and energetics of theWestern Pacific teleconnection pattern. J. Climate, 29, 6597-6616.

Trenberth, K. E., 1976: Spatial and temporal variations of the Southern Oscillation. Quart. J. Roy. Meteor. Soc., 102, 639653.

Walker, G. T., and E. W. Bliss, 1932: World Weather V. Mem. Roy. Meteor. Soc., 4, 53-84.

Wallace, J. M., and D. S. Gutzler, 1981: Teleconnection in the geopotential height field during the northern hemisphere winter. Mon. Wea. Rev., 109, 784-812.

Wang, B., R. Wu, and X. Fu, 2000: Pacific-East Asian teleconnection: How does ENSO affect East Asian climate? $J$. Climate, 13, 1517-1536.

Watanabe, M., and F.-f. Jin, 2002: Role of Indian Ocean warming in the development of Philippine Sea anticyclone during ENSO. Geophys. Res. Lett., 29, 116-1-116-4.

Zhang, T., J. Perlwitz, and M. P. Hoerling, 2014: What is responsible for the strong observed asymmetry in teleconnections between El Niño and La Niña? Geophys. Res. Lett., 41, 1019-1025.

Manuscript received 15 January 2021, accepted 31 March 2021

SOLA: https://www.jstage.jst.go.jp/browse/solal 